\section{The Role of Locus of Control Toward Arousal Procrastination Among Students}

Thoyyibatus Sarirah, Paramita Apsari

Jurusan Psikologi Universitas Brawijaya

Jalan Veteran Malang

email :Paramita_apsari@yahoo.co.id

thoyyibatus@ub.ac.id / ariexmr@gmail.com
Journal PSIKODIMENSIA

Volume 18, No. 1, Januari - Juni 2019

ISSN cetak : 1411-6073

ISSN online : 2579-6321

DOI 10.24167/psidim.v18i1.1676

\begin{abstract}
This study aims to determine the role of locus of control toward arousal procrastination among students. This study involved 400 students from Universitas Brawijaya. The sampling technique used accidental sampling.The measuring instrument used in this study is The Multidimensional Locus of Control IPC Scale (1981) to measure students' locus of control and the measuring instrument for arousal procrastination is adapted from General Procrastination Scale (GPS) Lay (1986). Data analysis using multiple linear regression analysis. Research result shows locus of control simultanneously contribute to arousal procrastination with signinificance of $0,001(p<0,05)$. Where the locus of control takes effect as much as 3,6 \% toward arousal procrastination, the other 96,4 \% is explained by other factors. According to the partial test, there are not found any role of the internal locus of control and external chance toward the arousal procrastination, however, a significant positive role is found on the external powerfull other toward arousal procrastination among students.
\end{abstract}

Keywords: locus of control, arousal procrastination, students

\section{PENDAHULUAN}

Perilaku penundaan dalam psikologi dikenal dengan istilah prokrastinasi. Orang-orang yang menunda (procrastinator) cenderung mengalami penundaan yang irasional serta memiliki well-being yang negative (Meier, Reinecke, \& Meltzer, 2017). Umumnya procrastinator atau orang yang melakukan prokrastinasi memiliki masalah dalam kesejahateraan psikologisnya (Sarirah, 2017) Prokrastinasi marak terjadi pada mahasiswa Steel (2010) 80-95 \% Mahasiswa terlibat prokrastinasi dan 75 $\%$ diantaranya mengakui dirinya sebagai seorang prokrastinator.

Berdasarkan studi pendahuluan
yang dilakukan peneliti dengan
melakukan wawancara pada 3

mahasiswa. Hasil dari wawancara yang telah dilakukan menunjukan bahwa mahasiswa tersebut kerap kali melakukan penundaan dalam melakukan pekerjaan. Mereka mengaku bahwa sering menunda-nunda dalam mengerjakan tugas akademik. Berikut ini adalah jawaban-jawaban yang diberikan mahasiswa mengenai perilaku penundaan yang dilakukan

"saya males ngerjainya tapi saya tetep mikirin tugasnya"

"saya lebih nyaman kalo ngerjain tugasnya pas mendekati deadline"

" saya ngerasa performa saya lebih bagus ketika ngerjain tugasnya mendekati deadline"

"biasanya saya belajarnya pas malam sebelum ujian biar gak lupa". 


\begin{tabular}{lrr} 
Berdasarkan & \multicolumn{2}{c}{ jawaban-jawaban } \\
yang diberikan oleh beberapa & oh \\
mahasiswa mereka juga mengaku bahwa \\
mereka melakukan penundaan pekerjaan \\
di semua jenis tugas. Salah & satu jenis \\
penundaan & adalah & arousal \\
procrastnatination di mana & mereka \\
melakukan prokrastinasi & demi \\
kesenangan dirinya. Di & Turki
\end{tabular}
ditemukan $14,7 \%$ orang dewasa adalah seorang arousal procrastinator (Ozer, Demir, \& Ferrari, 2009), sedanngkan Ernima (2016) menemukan menemukan subyek dalam penelitiannya adalah seorang arousal procrastination.

Bagaimana kita mengetahui individu melakukan prokrastinasi atau tidak dapat dilihat dari kepribadiannya (Tjundjing, 2008). Salah satu atribut kepribadian yang dimiliki seseorang ialah locus of control. Konsep locus of control pertama kali dicetuskan oleh Julian B Rotter pada tahun 1954. Menurut Rotter (1990) locus of control adalah ekspektasi individu mengenai peristiwa yang terjadi dalam hidupnya, apakah kejadian dalam hidup individu dikendalikan oleh dirinya sendiri (internal) atau kejadian yang ada dalam hidupnya dikendalikan oleh luar dirinya seperti orang lain yang dominan atau keberuntungan (eksternal).

Konsep locus of control Rotter tersebut kemudian dikembangkan oleh Levenson. Levenson mengembangkan teori Rotter dengan membedakan external locus of control menjadi dua yaitu external powerfull others dan external chance, dimana dalam alat ukurnya locus of control dianalisis secara perdimensi agar peneliti terhindar dari pemikiran tipologis. Alat ukur tersebut dikenal dengan The Multidimensional Locus of Control IPC Scale. IPC LOC Scale cocok untuk mengukur Locus of Control (LOC) pada orang dewasa (Kourmousi, Xythali, \& Vasilious, 2015).

Penelitian mengenai locus of control dengan prokrastinasi telah banyak diteliti. Individiu yang memiliki LOC internal cenderung kurang melakukan prokratinasi dibandingkan dengan individu yang memiliki LOC eksternal (Deniz, Tras, \& Avdogan, 2009).

Hal tersebut selaras dengan hasil penelitian Hartosujono (2012) yang menemukan adanya hubungan yang signifikan antara perilaku prokrastinasi dengan internal ataupun eksternal locus of control, dimana hubungan yang ditunjukan antara internal locus of control dengan prokrastinasi adalah hubungan yang positif dan terdapat hubungan yang negatif antara external powerfull dan external chance dengan prokrastinasi. Yang membedakan penelitian ini dengan penelitian sebelumnya, pada penelitian ini mengkaji topic spesifik dari prokrastinasi, yaitu arousal procrastination yang pada penelitian sebelumnya membahas prokrastinasi secara umum dengan locus of pada mahasiswa.

\section{METODE}

Desain penelitian ini menggunakan pendekatan kuatitatif. Jenis metode penelitian kuantitatif yang digunakan dalam penelitian ini adalah korelasional yaitu untuk mengetahui hubungan atau pengaruh dari variabel yang diteliti. Analisis data dalam penelitian ini menggunakan regresi linier berganda untuk mengetahui peran locus of control (internal, external powerfull others terhadap arousal procrastination pada mahasiswa.

Populasi dalam penelitian ini adalah mahasiswa angkatan 2014-2017. Sampel penelitian ini adalah 400 Mahasiswa yang diperoleh dari hasil perhitungan rumus slovin dan teknik pengambilan sampel yang digunakan ialah accidental sampling . Validitas reliabilitas penelitian menggunakan validitas isi dan cronbach alpha. 
Instrument yang digunakan dalam penelitian ini adalah sebagai berikut:

1. The Multidimensional Locus of Control IPS Scale (IPC LOC Scale. Instrumen penelitian yang digunakan adalah skala IPC Levenson yang telah di adaptasi oleh Sarirah (2011). Setelah dilakukan tryout terdapat 18 aitem yang lolos dari 24 aitem yang diujikan, yaitu terdiri dari 4 aitem internal control dengan nilai reliabilitas $0,742,6$ aitem external powerfull others dengan nilai reliabilitas 0,799 dan 8 aitem external chance dengan nilai reliabilitas 0,779 . Respon jawaban terdiri dari 4 alternatif jawaban yaitu STS (Sangat Tidak Setuju), TS (Tidak Setuju), S (Setuju), SS (Sangat Setuju) yang mengacu pada skala likert.

2. Arousal Procrastination. Instrumen penelitian yang digunakan adalah General Behavioral Procrastinasion Scale (GPS) Lay (1986) yang dilakukan proses transadaptasi ke dalam bahasa indonesia.Skal GPS Lay terdiri dari 16 aitem yaitu Favorable dan Unfovorable. Setelah dilakukan try out terdapat 16 aitem yang lolos dari 20 aitem, dengan nilai reliabilitas sebesar 0,890 Respon jawaban terdiri dari 4 alternatif jawaban yaitu STS (Sangat Tidak Setuju.), TS (Tidak Setuju), S (Setuju), SS (Sangat Setuju) yang mengacu pada skala likert.

Tahap analisa data dilakukan dengan melalui tahap uji asumsi dengan melakukan uji normalitas, uji linieritas, uji heteroskedastisitas dan uji multikolinieritas. Uji normalitas menggunakan One-Sampel Kolmogorov-Smirnov untuk mengetahui data yang telah terdistribusi secara normal atau tidak. Data dikatakan normal jika nilai deviasinya dari linieritas signifikansi > 0.05 ono \& Julianta 2011) - Uji linieritas dengan mencari persamaan garis regresi variabel $\mathrm{X}$ terhadap variabel Y. Uji heteroskedastisitas bertujuan untuk menguji apakah dalam model regresi terjadi ketidaksamaan varian dari residual satu pengamatan ke pengamatan yang lain dan uji multikolineritas untuk mengetahui. apakah antara variabel bebas terjadi gejala multikorelasi yaitu korelasi yang sangat tinggi atau sangat rendah yang ditunjukan oleh hubungan antara variabel bebas. Persyaratan untuk melakukan pengujian regresi ialah tidak terjadinya multikorelasi antara variabel independen (Sarjono \& Julianta, 2011). Uji hipotesis menggunakan analisis regresi linier berganda dengan bantuan SPSS versi 20.

HASIL

Analisis yang pertama adalah analisis deskriptif. Tujuan adanya statistik deskriptif ialah untuk memberikan gambaran mengenai penelitian dilihat dari data variabel yang diperoleh dari subyek penelitian 
Paramita Apsari: The Role of Locus of Control Toward ...

Tabel 1. Deskripsi Data Penelitian

\begin{tabular}{llll}
\hline Variabel & Statistik & Hipotetik & Empirik \\
\hline Internal LOC & Min & 4 & 5 \\
& Max & 16 & 16 \\
& SD & 10 & 12,45 \\
External Powerfull & Mean & 1,66 & 1,661 \\
Others & Max & 6 & 7 \\
& Mean & 24 & 22 \\
External Chance & SD & 15 & 13,49 \\
& Min & 2,5 & 2,478 \\
& Max & 8 & 10 \\
Arousal & Mean & 32 & 30 \\
Procrastination & SD & 20 & 18,77 \\
& Min & 3,33 & 3,184 \\
& Max & 16 & 22 \\
& SD & 64 & 58 \\
& & 40 & 39,83 \\
\end{tabular}

Berdasarkan data skor hipotetik dan empirik yang telah diperoleh dari kedua variabel penelitian dapat memberikan gambaran mengenai locus of control dan arousal procrastination subjek dengan melakukan pengkategorisasian.

Berikut adalah hasil dari pengkategorisasian kedua variabel :

Tabel 2. Nilai Mean Dan Standart Deviasi Locus Of Control

\begin{tabular}{lcc}
\hline & Mean & Standart Deviasi \\
\hline Internal Control & 12,45 & 1,661 \\
External Powerfull Others & 13,49 & 2,478 \\
External Chance & 18,77 & 3,184 \\
\hline
\end{tabular}

Berdasarkan nilai mean dan standart deviasi, terlihat bahwa external chance memiliki nilai mean dan standart deviasi tertinggi yaitu sebesar 18,77 dan
3,184. Artinya subjek dalam penelitian ini mayoritas memiliki kecenderungan external chance.

Tabel 3. Hasil Pengkategorisasian Arousal Procrastination

\begin{tabular}{cccc}
\hline Kategori & Daerah keputusan & Frekuensi & $\%$ \\
\hline Rendah & $\mathrm{X}<33,33$ & 51 & $12,75 \%$ \\
Sedang & $33,34 \leq \mathrm{X}<46,65$ & 308 & $77 \%$ \\
Tinggi & $46,66 \leq \mathrm{X}$ & 41 & $10,25 \%$ \\
\hline
\end{tabular}

Berdasarkan hasil pengkategorisasian yang telah dilakukan diketahui bahwa dalam penelitian ini mayoritas subyek arousal procrastination sedang yaitu sebanyak $77 \%$ atau 308 orang.

Hasil uji normalitas data penelitian menggunakan one sample kolmogorov-smirnov menunjukan nilai 
p yang diperoleh sebesar 0,851 , dimana $0,851 \geq 0,05$. Maka dapat diartikan bahwa data yang akan diolah dinyatakan terdistribusi secara normal.

Hasil uji linieritas menunjukkan bahwa nilai signifikansi arousal procrastination dengan internal sebesar 0,301 , arousal dengan powerfull others 0,085, dan arousal dengan chance 0,819 dimana nilai tersebut lebih besar dari pada 0,05 sehingga dapat disimpulkan data antara variabel $\mathrm{X}$ dan $\mathrm{Y}$ adalah linier.

Uji multikolinearitas dilakukan untuk mengetahui apakah antara variabel bebas terjadi gejala multikorelasi yaitu korelasi yang sangat tinggi atau sangat rendah yang ditunjukan oleh hubungan antara variabel bebas, berikut adalah hasil analisis yang telah dilakukan

Tabel 4. Uji Multikolinearitas

\begin{tabular}{llll}
\hline Variabel Bebas & Tollerance & VIF & Keterangan \\
\hline Internal locus of control & 0,960 & 1,042 & Non Multikol \\
External Powerfull Others & 0,701 & 1,426 & Non Multikol \\
External chance & 0,726 & 1,378 & Non Multikol \\
\hline
\end{tabular}

Berdasarkan hasil analisis yang telah dilakukan didapat nilai tollerance internal 0,960 , powerfull other 0,701, dan chance sebesar 0,726 dimana nilai tersebut lebih dari 0,1 dan nilai VIF internal 1,042, powerfull others 1,426, dan chance 1,378 dimana nilai tersebut tidak lebih dari 10 sehingga dapat disimpulkan antar variabel bebas tidak terjadi multikolinearitas.

Berdasarkan hasil analisis uji asumsi yang dilakukan, diketahui bahwa telah memenuhi syarat untuk melakukan uji hipotesis regresi berganda. Berikut adalah hasil analisis regresi berganda

Tabel 5. Regresi berganda

\begin{tabular}{ccccc}
\hline Model & $\boldsymbol{B}$ & Beta & $\boldsymbol{t}$ & Sig \\
\hline (Constant) & 37,806 & & 12,427 & .000 \\
Internal & $-0,300$ & $-0,085$ & $-1,696$ & .091 \\
$\begin{array}{c}\text { Powerfull } \\
\text { Others } \\
\text { Chance }\end{array}$ & 0,377 & 0,164 & 2,801 & .005 \\
\hline
\end{tabular}

Berdasarkan hasil uji regresi berganda ditemukan nilai persamaan regresi sebagai berikut $\mathrm{Y}=37,806+(-$ $0,300)+0,377+0,036$.

Berdasarkan hasil uji $t$ diketahui nilai signifikansi yang diperoleh dari nilai internal control sebesar .0091, external powerfull others sebesar 0,005 dan external chance sebesar .729 . Berdasarkan hasil tersebut diketahui bahwa hanya external powerfull others yang berperan terhadap arousal procrastination $\mathrm{p}=.005(\mathrm{p}<.05)$, yang artinya H02 ditolak dimana arah hubungannya positif $\mathrm{B}=.377$.

Koefisien Determinasi

Berdasarkan hasil uji koefisien determinasi diperoleh nilai sebesar .036 , artinya locus of control dapat mempengaruhi arousal procrastination sebesar 3,6\% 


\section{DISKUSI}

Penelitian ini bertujuan untuk mengetahui peran dari locus of control (internal, external powerfull other dan external chance). Berdasarkan hasil analisis data yang telah dilakukan menunjukan bahwa variabel external powerfull others menunjukan peran positif yang signifikan terhadap arousal procrastination artinya semakin tinggi nilai external powerfull others seseorang maka semakin tinggi pula tingkat arousal procrastinationnya begitupun sebaliknya. Hal ini mendukung pendapat Findley dan Cooper (Nugrasanti 2006) mengenai karakteristik individu dengan external powerfull others yaitu kemampuan dalam mengendalikan diri dan lingkungan yang rendah, perasaan takut akan perbuatan yang dilakukannya, membutuhkan bantuan serta dukungan dari orang lain. Individu dengan external powerfull others cenderung bergantung pada orang lain dan enggan untuk berusaha sendiri (Phares, 1978, dalam Nugrasanti 2006). Oleh karena itu, individu dengan external powerfull others atau yang memiliki kepercayaan tentang apa yang terjadi dalam hidup dikendalikan oleh orang lain yang lebih berkuasa selalu membutuhkan sokongan dalam melakukan segala sesuatu salah satunya dalam mengerjakan tugas sehingga ia cenderung akan melakukan prokrastinasi apabila tidak mendapatkan bantuan atau dukungan dari orang lain.

Berbeda dengan external powerfull others yang memiliki peran yang signifikan terhadap arousal procrastination, pada penelitian ini menunjukan bahwa internal locus of control tidak berperan secara signifikan terhadap arousal procrastination. Hasil ini mendukung penelitian Philip (2012) yang menemukan tidak ada hubungan antara internal locus of control dengan prokrastinasi. Individu yang memiliki internal locus of control percaya bahwa apapun hasil yang diperoleh adalah berkat usaha dan kompetensi yang dimilikinya, bukan karena faktor eksterna sehingga individu yang memiliki internal control lebih giat untuk berusaha meraih keinginan yang ingin dicapai serta rela untuk menunda kesenangan saat ini untuk tujuan masa depan. (Phares, dalam Nugrasanti 2006).

Individu yang memiliki locus of control internal akan terhindar dari prokrastinasi karena ia memiliki kesiapan diri dalam mengerjakan tugas sehingga membuatnya termotivasi dalam mengerjakan tugas. Hal ini sesuai dengan temuan Setiawan, Kurniawati, dan Fitriani (2015) yang menemukan bahwasannya terdapat peran internal locus of control terhadap self efficacy.

Penelitian ini menunjukan bahwa dimensi external chance tidak berperan terhadap arousal procrastination. Hal ini mendukung penelitian Boysan dan Kiral (2017) yang tidak menemukan hubungan yang signifikan antara external chance dengan prokrastinasi.

Berdasarkan nilai mean dan standart deviasi locus of control tertinggi diketahui bahwa mayoritas subyek dalam penelitian ini memiliki kecenderungan external chance. Sementara itu, berdasarkan hasil pengkategorisasian yang dilakukan pada variabel arousal procrastination menunjukan bahwa dari 400 subjek penelitian mayoritas memiliki arousal procrastination kategori sedang, namun terdapat pula yang memiliki skor tinggi. Jadi hasil penelitian ini memperkuat hasil penelitian yang dilakukan oleh Ernima (2016) dimana dalam penelitiannya menunjukan bahwa tingkat arousal procrastination pada mahasiswa ekonomi UNJ lebih dominan dibandingkan prokrastinasi jenis lain.

Berdasarkan hasil koefisien determinasi diketahui bahwa variabel indepent dapat mempengaruhi variabel dependent sebesar 3,6\% dan sisanya $94,4 \%$ dijelaskan oleh faktor lain yang tidak diteliti. Hal ini menunjukan variabel X memiliki pengaruh yang kecil 
terhadap variabel Y. Faktor lain yang mungkin dapat mempengaruhi perilaku arousal procrastination ialah seperti sensation seeking dan boredom proneness (Ferrari, 2005).

\section{SIMPULAN}

Berdasarkan hasil analisa data yang telah dilakukan pada mahasiswa, peneliti dapat menyimpulkan bahwa external powerfull others berperan positif terhadap arousal procrastination pada mahasiswa. Semakin tinggi kecenderungan external powerfull others yang dimiliki mahasiswa semakin tinggi pula arousal procrastination yang dimilikinya. Sedangkan dimensi internal

\section{REFERENSI}

Bono, T. A. (2001). Relationship of core self-evaluations traits-selfesteem, generalizedself-efficacy, locus of control, and emotional stability with job satisfaction and job performance: A meta-analysis. Journal of Applied Psychology, 86(1). 80-92.

Clarry H. Lay, H. C. (1995). Trait procrastination and the big five factors of personality. Personality And Individual Differences 18(4). 481-490.

Deniz, M. E., Tras, Z., \& Avdogan, D. (2009). An investigation of academic procrastination, locus of control and emotional intelligence. Educational Sciences: Th eory \& Practice, 149(2). 623-632.

Boysan, M., Kiral, E. (2017). Associations between procrastination, personality, perfectionism, self-esteem and locus of control. British Journal locus of control dan external chance tidak berperan terhadap arousal procrastination pada mahasiswa.

Berdasarkan hasil penelitian dan pembahasan yang telah dijelaskan sebelumnya, maka peneliti selanjutnya diharapkan untuk memperluas ruang lingkup penelitian tidak terbatas pada satu universitas saja sehingga dapat menjadi dasar generalisasi untuk mahasiswa lainnya, serta diharapkan untuk memperhatikan faktor-faktor lain yang dapat mempengaruhi arousal procrastination seperti self handicapping, self esteem, sensation seeking, dan boredom proneness.

of Guidance \& Counselling. 45(3). 284-296.

Ernima, R.Y. (2016). Locus of control dan prokrastinasi pada mahasiswa pendidikan ekonomi angkatan 2013 Fakultas Ekonomi Universitas Negeri Jakarta. Jurnal Pendidikan Ekonomi dan Bisnis 4(2), 87-106.

Ferrari, J. R. (2005). Prevalence of procrastination in the united states, united kingdom, and australia: arousal and avoidance delays among adult. North American Journal of Psychology 7(1), 1-6.

Hartosujono. (2012). Perilaku prokrastinasi mahasiswa ditinjau dari locus of control. Jurnal SPIRITS 3(1), 28-42.

Kourmousi, N., Xythali, V., \& Vasilious, K. (2015). Reliability and validity of the multidimensional locus of control IPC scale in a sample of 3668 greek educators. social sciences, 4, 1067-1078. 
Lay, C. H. (1986). At least, my research article on procrastination. Journal Of Research In Personality, 20,474-495.

Meier, A., Reinecke, L., \& Meltzer, C. E. (2017). "Facebocrastination"? predictors of using facebook for procrastination and its effects on students' well-being. Computers in Human Behavior, 64, 65-76.

Nugrasanti, R. (2006). Locus of conrol dan prokrastinasi akademik mahasiswa. Jurnal Provitae, 2(1), 25-3.

Philips, M. (2012). Does locus of control task interest have an effect on procrastination? Journal of Learning and Motivation: 50(1),1-19..

Rotter, J. B. (1990). Internal versus external control of reinforcement. American Psychologist, 45(4),489-493.

Sarirah, T. (2011). Pengaruh Belief irasional dan locus of control terhadap prokrastinasi pada guru. Tesis Tidak Dipublikasikan, Universitas Indonesia, Depok.

Sarirah, T. (2017). Apakah prokrastinator sejahtera psikologisnya?. Studi pada Dosen di universitas x Malang. INSAN Jurnal Psikologi dan Kesehatan Mental, 1 (2). 134-140.

Sarjono, H., \& Julianta, W. (2011). SPSS vS LISREL sebuah pengantar, aplikasi untuk riset. Jakarta: Salemba Empat .

Setiawan, A.I., Kurniawati, Y., \& Fitriani, A. (2015). Internal locus of control dan self-efficacy pemain bola basket dalam melakukan free throw. Mediapsi. 1(1). 17.27.

Steel, P. (2010). Arousal, avoidant and decisional procrastinators: Do they exist? Personality and Individual Differences, 48, 926934.

Tjundjing, I. K. (2008). I Love you tomorrow: prokrastinasi akademik dan manajemen waktu. Indonesian Psychological Journal, 23(2), 109-119. 